\title{
XAMANISMO: PROCESSOS SOCIOCULTURAIS E HISTÓRICOS NO MUNDO DOS ESPÍRITOS DO POVO MARUBO NO VALE DO JAVARI.
}

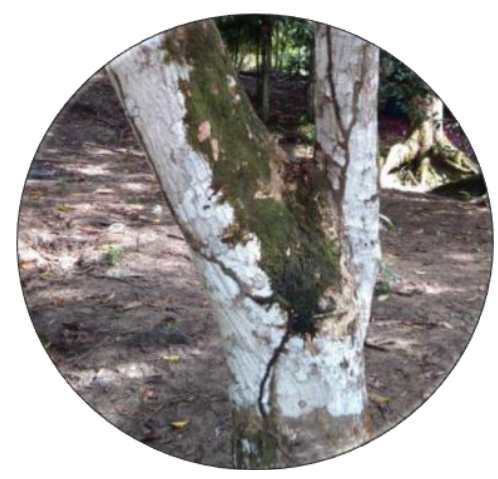

Priscila Rocha Santos ${ }^{1}$

Heloísa Helena Corrêa da Silva

\section{Resumo}

O artigo analisa os processos socioculturais e históricos do povo Marubo do Vale do Rio Javari, região fronteiriça da Pan-Amazônia, que se utiliza do xamanismo como elemento central para a estruturação social, relações de gênero e sobrevivência enquanto povo. Os processos de magia, práticas corporais e cura através do exercício do xamanismo da etnia Marubo no Vale do Javari atravessaram diferentes momentos históricos e ainda na atualidade são utilizadas como momentos de passagens históricas, decisões políticas e mudanças socioculturais, consolidando a posição de destaque ao citado povo no Vale do Javari. Para o alcance da análise procedeu-se com revisões bibliográficas e entrevistas semiestruturadas, que possibilitaram demonstrar que as relações socioculturais e históricas são também responsáveis pela definição de papéis entre homens e mulheres; onde o mundo dos espíritos é explicitamente do domínio masculino, enquanto para as mulheres é reservado o mundo doméstico. Nesse contexto, as mulheres conseguem ouvir os espíritos tardiamente do ponto de vista etário; após a menopausa, quando não são mais consideradas impuras. A inserção da mulher no mundo dos espíritos tem o objetivo de instruir os mais novos o que os espíritos ensinam.

Palavras-chave: Xamanismo. Processos históricos e socioculturais. Marubo.

1 Bacharel em Odontologia. Trabalho com Populações Indígenas do Vale do Javari. Docente do Instituto de Natureza e Cultura - INC, da Universidade Federal do Amazonas/UFAM. Mestranda no Programa de Pós-Graduação em Sociedade e Cultura na Amazônia - PPGSCA/UFAM.

2 Professora da Universidade Federal do Amazonas. Orientadora de Mestrado e Doutorado no Programa de Pós Graduação Sociedade e Cultura na Amazônia - PPGSCA. 


\begin{abstract}
The article analyzes the socio-cultural and historical processes of the Marubo people of the Javari River Valley, the border region of Pan-Amazonia, which uses shamanism as a central element for social structuring, gender relations and survival as a people. The processes of magic, corporal practices and healing through the exercise of Marubo shamanism in the Javari Valley have crossed different historical moments and are still used as moments of historical passages, political decisions and sociocultural changes, consolidating the position of prominence people in the Javari Valley. In order to reach the analysis, we proceeded with bibliographical reviews and semi-structured interviews, which enabled us to demonstrate that socio-cultural and historical relations are also responsible for the definition of roles between men and women; where the world of spirits is explicitly male, whereas for women the domestic world is reserved. In this context, women are able to listen to spirits belatedly from the age point of view; after menopause, when they are no longer considered impure. The insertion of the woman in the world of the spirits has the purpose to instruct the youngest what the spirits teach.
\end{abstract}

Keywords: Shamanism. Historical and sociocultural processes. Marubo.

\title{
INTRODUÇÃO
}

Esse artigo analisa através de pesquisa bibliográfica e de campo, o mundo dos espíritos, tendo como participantes da pesquisa, grupo do povo Marubo que habita área fronteiriça da Pan-Amazônia.

Utilizou-se a entrevista estruturada como instrumental de coleta das narrativas, que possibilitaram as autoras a perceber as noções de cultura e etnicidade relacionadas às práticas xamânicas e a importância da magia nos processos socioculturais e históricos da etnia Marubo do Vale do Javari.

Nesse contexto, também se percebeu que as diferenças biológicas têm visibilidade e determinam papeis sociais entre eles, forjando a compreensão de gênero como uma construção social. E, embora de fato as pesquisadoras reconhecerem as conexões e diferenças entre gênero e divisão social dos papéis, interessa para este artigo analisar a questão no bojo dos processos socioculturais e históricos. 
Segue-se na organização social dos Marubo a divisão "natural” do trabalho em que a mulher se vê excluída dos papéis sociais mais prestigiosos (ROSALDO, 1974), um deles o xamanismo. De acordo com esse autor existe uma série de dicotomias nos estudos antropológicos causados pela tradição teórica que reduz a mulher ao papel de reprodutora entre elas: a mulher privada versus o homem público (ROSALDO, 1974) e a mulher procriadora biológica versus o homem procriador social e cósmico (COLPRON, 2005).

Para contestar a oposição homem produtor vs. mulher reprodutora, diversos autores sublinharam o papel procriador do homem no plano simbólico: por meio da função de xamã, o homem se reserva o controle metafísico sobre a reprodução. A mulher, que já detém esse privilégio no plano físico, não poderia acumular esses papéis. (BELLIER, 1991).

O xamanismo na comunidade indígena Marubo é uma prática exercida quase que exclusivamente por homens, assim como as demais comunidades indígenas da Amazônia. Algumas pesquisas etnográficas apresentam evidências da presença de mulheres xamãs em certas sociedades da Amazônia, mas na maioria delas são retratadas apenas de passagem (COLPRON, 2005). Entendendo passagem de acordo com CARDOSO DE OLIVEIRA, que instrui sobre as passagens históricas e socioculturais e grandes decisões políticas dos povos indígenas realizarem-se em meio às festas e rituais xamânicos.

A crença em poderes mágicos pode ser interpretada como um fenômeno sociocultural, sendo recorrente em inúmeras sociedades. Suas origens remontam a tempos e espaços amplamente divergentes, aspecto que funda um consenso entre os estudiosos sobre um conjunto de práticas e representações mágicas inerentes à todas culturas. Tais práticas perpetuam-se ao longo do tempo, influenciando-se e adaptando-se através 
de uma relação dinâmica junto a outros saberes sociais. (SANTOS, 1999, p. 11).

Os escritos e relatos dos povos indígenas amazônicos defendem a ideia que o poder místico, a locomoção e a comunicação com o mundo dos espíritos é uma prática exercida essencialmente por homens, associando a função xamã ao elo entre o mundo dos espíritos, o curador, o caçadorguerreiro, paradigma da masculinidade. (COLPRON, 2005)

\section{METODOLOGIA}

Para esta pesquisa foram utilizadas entrevistas semi-estruturadas com alguns indivíduos da etnia Marubo, oriundos da aldeia São Sebastião e Boa Vista, localizadas no rio Alto Curuçá e Médio Ituí no Vale do Javari, mas atualmente localizados em uma maloca na BR 307, uma rodovia que se encontra no estado do Amazonas, ligando os municípios de Atalaia do Norte e Benjamin Cosntant.

Foram entrevistados o pajé Aramimpa e seu cunhado Pedro Duarte Comapa que possui o chamado ao xamanismo, mas nunca continuou o aprendizado para se tornar pajé devido à morte do tio, Suzete Matias Duarte e outros familiares próximos para termos como referência os diferentes pontos de vistas dos ambos os gêneros em relação ás práticas xamânicas do povo Marubo. Para as entrevistas foram utilizados gravador com posterior transcrição e caderno de campo para realizar as anotações, na entrevista de Aramimpa, contamos com a ajuda de um tradutor Marubo.

O Xamã é aquele que escuta o espírito que irá trazer a cura, as técnicas de cura são atos de purificação ritual do enfermo e seu grupo familiar que visam livrá-los das forças disruptivas que os ameaçam. Simultaneamente, representam formas de exercício do poder sobre os membros da sociedade, que preconizam a austeridade o reforço das disciplinas do corpo e do espírito, assim como promovem o controle moral 
dos mais velhos sobre os mais novos e dos homens sobre as mulheres (GARNELO 2003).

As mulheres xamãs são pouco reconhecidas e frequentemente omitidas em relatos, poucos autores, como Colpran (2005) e Cicarone (2004) realizaram uma pesquisa etnográfica tendo como o objetivo as mulheres xamãs. Alguns autores como Bellier (1991) afirmam que "apenas os homens podem ser curandeiros", atividades que exercem com a ajuda de bebida alucinógena ayahuasca ${ }^{3}$ e rapé ${ }^{4}$. Inclusive durante as entrevistas esta mesma afirmação foi dita por quase todas as pessoas escutadas, apenas uma mencionou que as mulheres também poderiam escutar os espíritos em uma idade mais tardia, e apenas com o objetivo de ensinar aos mais novos, fato encontrado em algumas referências etnográficas acerca de outras culturas amazônicas onde casos excepcionais de mulheres xamãs descritas como de segunda ordem e com poderes menores (OVERING 1986, MURPH E MURPH 1974) que se desenvolvem após a menopausa. O Xamanismo é uma prática que passa de pai para filho, só o homem pode se tornar pajé, se ele tiver mais de um filho, só um terá o chamado. Ele nasce diferente dos outros, já nasce com o dom, e o pajé percebe porque o filho tem medo, não come certas comidas, possui um olhar diferente, tem sonhos e fala quando dorme.

"Se nenhum dos filhos possuírem o dom, ou não nascer homens, um sobrinho deverá se tornar pajé, o dom está presente na família, é coisa de sangue." (Aramimpa)

Em várias afirmações durante as entrevistas pode-se notar que a mulher pode atrapalhar o espírito durante o processo de cura, como por

\footnotetext{
3 Ayahuasca (do quíchua aya, que significa 'morto, defunto, espírito', e waska, 'cipó', podendo ser traduzido como "cipó do morto" ou "cipó do espírito") é uma é uma bebida produzida a partir da combinação da substâncias alteradoras da consciência que induz ao estado xamânico.

${ }^{4}$ Rapé é o tabaco em pó para inalar, é um pó resultante de folhas de tabaco torradas e moídas, por vezes misturadas a outros componentes.
} 
exemplo, durante a prática do xamanismo, as mulheres Marubo que estiverem no período de menstruação não podem entrar na maloca.

$\mathrm{Na}$ entrevista também foi relatado que "ninguém pode ter tido relação sexual com mulher antes da pajelância, se fizeram tem que tomar um 'copão', uma masquita, um pau que raspa a madeira, tem cheiro de mato, ele toma para sair o cheiro da mulher se fez sexo antes, tem que ser feito antes de se enfeitar e se preparar” (Pedro Comapa).

"Quando o menino que se tornará pajé, se torna homem e o espirito começa a atoar ${ }^{5}$ nele, ele passa por uma iniciação, um período de seis meses, e os curandeiros ${ }^{6}$ passam a cuidar dele, não pode ter menina atrás dele, ou seja, ele não pode se contaminar com mulher" (Pedro Comapa).

O mundo dos espíritos é de domínio masculino, Descrito por Colpran (2005) como "transgressor de fronteira (animal/humano, morte/vida etc.), que não é constrangido por sua biologia, pode ultrapassar suas barreiras corporais.” As mulheres não podem ultrapassar essa barreira pela impureza que existe nela imposta por sua biologia, como a menstruação e o liquido amniótico secretado durante o parto.

O papel da mulher em relação ás práticas xamãnicas se demonstra aos ensinamentos dos mais novos quando elas chegam à menopausa e se tornam mais "puras", sendo capazes de escutar os espíritos e quando o iniciante a pajé já está se acostumando com os espíritos e já não saem mais dele, a mãe ou a avó se tornam responsáveis por sua alimentação. Não pode ser qualquer pessoa a fazer a comida, deve ser uma mulher que o criou. Ele precisa comer sozinho, não pode comer junto com os demais, só

${ }^{5}$ Atoar - verbo referente à ação do espírito no pajé. "Não é o pajé que cura, é o espírito que 'atoa' nele."

${ }^{6}$ É a pessoa que reza durante a pajelância e escuta o que o pajé fala através dos espíritos. 
pode se juntar aos demais na hora da alimentação depois que tiver se acostumado aos espíritos.

De acordo com CORRÊEA DA SILVA (2015), alguns antropólogos ${ }^{7}$ afirmam que as histórias dos povos indígenas são sobre um tempo mitológico rico, eles recriam suas histórias a partir de eventos mitológicos, e, nesses eventos mitológicos as mudanças históricas e socioculturais são decididas, sendo fato constato no caso de interesse do artigo.

Apesar da agressão dos colonizadores, que ruiu nos últimos trezentos anos com as organizações sociais dos povos indígenas, o xamanismo é um dos fatores que contribui para as recomposições e afirmações de poder. A recomposição etnográfica mostra-se constante entre os povos indígenas, principalmente, na Pan-Amazônia, onde as decisões políticas são também socioculturais e o espaço onde eles encontram apoio para suas necessidades.

\section{CONSIDERAÇÕES FINAIS}

Pode-se concluir que os processo históricos e socioculturais estão imbricados nas relações sociais que também definem os papéis dos homens e das mulheres e os aspectos de poder entre eles estão presentes fortemente nas sociedades indígenas, em particular da etnia Marubo, onde o mundo dos espíritos é explicitamente do domínio masculino, transformando tal domínio em poder, que em diferentes momentos históricos reafirma e consolida o destaque desse povo no Vale do Javari. As formas de exercício do poder sobre os membros dessa sociedade são representados através do xamanismo.

${ }^{7}$ Ver MELATTI, Julio Cezar.

http://www.juliomelatti.pro.br/areas/15altama.pdf. 


\section{Referências}

BELLIER, Isabelle. La Responsabilidad de Las Mujeres Encinta Respecto de Los Chamanes. In: El Temblor y l aluna: ensayo sobre las relaciones entre las mujeres y los hombres mai-huna. 1991.

BRIGHENTI, Clovis Antonio. Xamanismo, Cultura e Gênero: Apropriação e Transposição de Práticas e Saberes a Partir da Experiência Mbya Guarani. Canoas n.23 p.67-80 jan./jun. 2011

CICCARONE, Celeste. Drama e Sensibilidade: Migrações, Xamanismo e Mulheres Mbya. Revista de índias, v. LXIV, n. 230, p. 81-96, 2004.

COLPRON, Anne-Marie. Monopólio Masculino do Xamanismo Amazônico: O Contra-Exemplo das Mulberes Xamã Shipibo-Conibo. MANA 11(1):95-128, 2005.

GARNELO, Luiza. Poder, Hierarquia e Reciprocidade: Saúde e Harmonia entre os Baniwa do Alto Rio Negro. In: Coleção Saúde dos Povos Indígenas. Rio de Janeiro: Editora Fio Cruz, 2003.

MONTEIRO, Maria Teresa Ferreira. De bruxa a enfermeira: uma herança do gênero feminino. Dissertação de Mestrado. Rio de Janeiro, dez 2000.

MURPHY, Yolanda; MURPHY, Robert. Women of the forest. New York and London: Columbia University Press 1974.

MELATTI. Julio Cezar. Disponível em: http://www.juliomelatti.pro.br/areas/15altama.pdf.

NASCIMENTO, Solange Pereira do; TORRES, Iraildes Caldas. O Ritual de Passagem da Moça Nova na Etnia Sateré-Mawé a Partir da Narrativa de Uma Líder Tuxaua. In: Caderno de Resumos [expandido] do $1^{\circ}$ Encontro de Estudos Sobre as Mulheres da Floresta: Gênero, Trabalho e Meio Ambiente. Manaus. Editora da Universidade Federal do Amazonas, p. A203, 2009.

OVERING, Joanna. Men control women? The Cath 22 in the Analysis of Gender. International Journal of Moral and Social Studies, 1(2):135-156, 1986.

ROSALDO, Michelle Zimbalist. Mulher, Cultura e Sociedade: Uma Visão Teórica. In: Mulher, Cultura e Sociedade. Editora Paz Terra, 1974.

SILVA, Semíramis Corsi. A imagem da mulher feiticeira como expressão da diferença de gênero em Roma: os poemas de Horácio e Ovídio. 2004. Disponível em: http://www.klepsidra.net/klepsidra27/feiticaria.htm. Visualizado em: 13/05/16. 